\title{
Evaluation of enamel by scanning electron microscopy green led associated to hydrogen peroxide $35 \%$ for dental bleaching
}

\author{
Juliana S. C. Monteiro ${ }^{a, b, e}$, Susana C. P. S. de Oliveira ${ }^{a, b}$, Fátima A. A. Zanin ${ }^{\text {a,b,d }}$, Gustavo M. P. \\ Santos $^{c}$, Fernando J. P. Sampaio ${ }^{\text {a,b, }}$, Rafael Araújo Gomes Júnior ${ }^{c}$, Maria F. M. Gesteira ${ }^{\text {a,b }}$, \\ Marcos A. Vannier-Santos ${ }^{c}$ and Antônio L. B. Pinheiro* ${ }^{\text {a,b,d }}$. \\ a Center of Biophotonic, School of Dentistry, Federal University of Bahia, Salvador, BA, Brazil, \\ 40110-150; \\ b National Institute of Optics and Photonics, São Carlos, SP, Brazil, 13560-970 \\ c Laboratory of Parasite Biology, Centro de Pesquisas Gonçalo Muniz, Fundação Oswaldo Cruz \\ FIOCRUZ, Salvador, BA, INCT-INP e TAM, Brazil. \\ d Brugnera \& Zanin Institute, São Paulo, SP, Brazil 01434-000 \\ e Department of Biology, Estate University of Feira de Santana, Feira de Santana, BA, Brazil, \\ 44036-900.
}

\begin{abstract}
Dental bleaching is a frequently requested procedure in clinical dental practice. The literature is contradictory regarding the effects of bleaching agents on both morphology and demineralization of enamel after bleaching. The aim of this study was to analyze by SEM the effect of 35\% neutral hydrogen peroxide cured by green LED. Buccal surfaces of 15 pre-molars were sectioned and marked with a central groove to allow experimental and control groups on the same specimen. For SEM, 75 electron micrographs were evaluated by tree observers at 43X, 220X and 1000X. Quantitative analysis for the determination of the surface elemental composition of the samples through X-ray microanalysis by SEM was also performed. The protocol tested neither showed significant changes in mineral composition of the samples nor to dental enamel structure when compared to controls. SEM analysis allowed inferring that there were marked morphological differences between the enamel samples highlighting the need for the use of the same tooth in comparative morphological studies. The tested protocol did not cause morphological damage the enamel surface when compared to their respective controls.
\end{abstract}

Keywords: SEM, Light, Dental Bleaching, Hydrogen Peroxide

\section{INTRODUCTION}

The aesthetic dental bleaching is a minimally invasive procedure. However, tooth bleaching is a procedure with specific indications where its protocol must be individualized ${ }^{1}$. There persistent concerns in research with tooth bleaching, subtends these concerns is security, comfort and better esthetic outcomes for patients ${ }^{2,3}$.

The techniques of tooth bleaching consists of a redox reaction where hydrogen peroxide is decomposed and gives rise to oxygen. These reactions can occur by enzymatic catalysis, thermal, light, laser or LED. The techniques are evolving, as well as bleaching agents. Searches are investigating these adverse tooth bleaching materials and periodontal effects. Recently the equipment based light emitting diode LED, has facilitated the clinical procedure of tooth bleaching and promotes comfort and security ${ }^{4}$.

*albp@ufba.br; phone 5571 3283-9010; fax 5571 3283-9010; www.laser.odontologia.ufba.br

Mechanisms for Low-Light Therapy IX, edited by Michael R. Hamblin, James D. Carroll, Praveen Arany, Proc. of SPIE Vol. 8932, 893214 - @ 2014 SPIE · CCC code: 1605-7422/14/\$18 · doi: 10.1117/12.2038558 
In a study using different curing systems and three different bleaching agents in concentrations of $35 \%$ hydrogen peroxide, it was found that the light source is important in dental bleaching. Reported a greater difference in bleaching with a light emitting diode [(LED) / laser] than without it (in $35 \%$ gel HP) with a change of shade guide value of 4.8 versus 3.8 units $^{5}$.

The effect of desensitizing agent may be held before the session of tooth whitening because this maneuver does not affect the mechanism of action of the bleaching agent, hydrogen peroxide $35 \%$, on the surface of dental enamel ${ }^{6}$.

Accelerate the redox reaction shortens the application of bleaching agents on tooth structure. Therefore, tooth whitening in a single session provides a decrease in the contact time of the bleaching agent with the dental unit. If the patient has sensibility this can be easily controlled ${ }^{7}$.

The $\mathrm{pH}$ is an important factor for the study of bleaching agents and their effects on the loss of minerals in the tooth surface ${ }^{7}$. The analysis of enamel structure performed by scanning electron microscopy, also has shown marked differences in the structure of enamel in different samples ${ }^{8}$.

The aim of this study was to analyze the surface of enamel after use of hydrogen peroxide to $35 \%$ by scanning electron microscopy (SEM). For both, were treated with hydrogen peroxide premolars, employed the concentration of $35 \%$ compared to the controls and the possible structural changes caused by photoactivated bleaching substances by the green LED.

\section{METHODOLOGY}

\subsection{Sample preparation}

In this study, we used 15 human teeth, premolars removed surgically, which had as selection criteria the integrity of the crown. The teeth were prepared until the beginning of experimento 9 . We performed a section of dental crowns units through vertical cut towards occluded cervical, in the area corresponding to the central sulcus of the tooth crown separating the buccal and palatine. To carry out this study, the teeth still had their faces interrupted by a cleft palate splitting into hemi-faces: buccal-mesial subjected to the action of hydrogen peroxide (35\%) their distal hemi-faces were used as negative control.

- Exp Group I - Hydrogen peroxide (35\%) photoactivated with LED green 15 hemi-buccal-mesial faces of the dental crown.

- Control Group I - 15-sided hemi-buccal distal dental crown.

\subsection{Photoactivated bleaching protocol}

The teeth were fixed in "stubs" (metal brackets used to hold the specimens in SEM) and had their faces distal (control) and slit covered with Topdam (gingival barrier, FGM, Joinville, SC). The substance used was whitening Whiteform Perox Red ${ }^{\circledR}$ (Formula Action \& Pharmaceutical Laboratory Ltd - São Paulo-SP), the concentration (35\%), was manipulated specifically for this study, retains the red color and is presented in syringes with disposable tips. The gel was applied in uniform layer thickness measured with probe was (sswhite - DUFLEX, Rio de Janeiro, RJ) of approximately $1 \mathrm{~mm}$ in G.Exp.I. Then, we performed activation gel with LED (Light Green D - Kondortech, São Carlos, SP, Brazil), the device was positioned at a distance of $5 \mathrm{~mm}$ from the tooth surface, measured with a millimeter ruler (Maqueira, Maringa, PR, Brazil). The protocol elected ${ }^{10}$, the parameters of LED in Table1. 
Table 1: Summary of the parameters used on the study.

\begin{tabular}{l|c}
\hline Parameters & LED D-Light Green \\
\hline Power Density & $180 \mathrm{~mW} / \mathrm{cm}^{2}$ \\
Wavelength & $520 \pm 30 \mathrm{~nm}$ \\
Mode & $\mathrm{CW}$ \\
Exposure Time (s, per session) & 540 \\
\hline
\end{tabular}

\subsection{Scanning Electron Microscopy (SEM)}

Upon completing the photoactivated bleaching procedure, their tooth faces were dried at $50^{\circ} \mathrm{C}$ for 24 hours. Sample analysis was performed using the Scanning Electron Microscope (JEOL JSM 6390 LV), belonging to the Electron Microscopy Unit of the Gonçalo Moniz Research Center - FIOCRUZ - Salvador, Bahia. The specimens thus prepared were fixed in small metal brackets "stubs" through a carbon double-sided tape and then analyzed. There was the standardization of the region for analysis, being given the middle third of the tooth crown, being an intermediate region where there is less likelihood of physiological wear of tooth enamel.

Electron micrographs were acquired dental crowns using the program "the JEOL SEM Control Program" and obtained an increase of X 43, X 220 and X 1000 in all study groups, in order to allow detailed qualitative evaluation of the surface enamel. The characteristics of the morphology of the tooth enamel assessed in SEM was according to the qualitative assessment performed by three examiners, where the evaluation criterion and comparative examination of palatal groups and their controls. We also carried out a quantitative determination of the atomic composition of the surface of the samples through microanalysis with the aid of a scanning electron microscope.

\subsection{Statistical analysis}

For the statistical analysis it was used the computer software 'GraphPad Prism', the test was part listed the Kruskal-Wallis test, it was considered as statistically significant results with $\mathrm{P}<0.05$.

\section{RESULTS}

The quantitative assessment of the distribution of calcium and phosphorus in the tooth surface can be observed in Fig. 1, which also showed no statistically significant differences. The figures for calcium and phosphorus are graphically represented in Fig.2. 

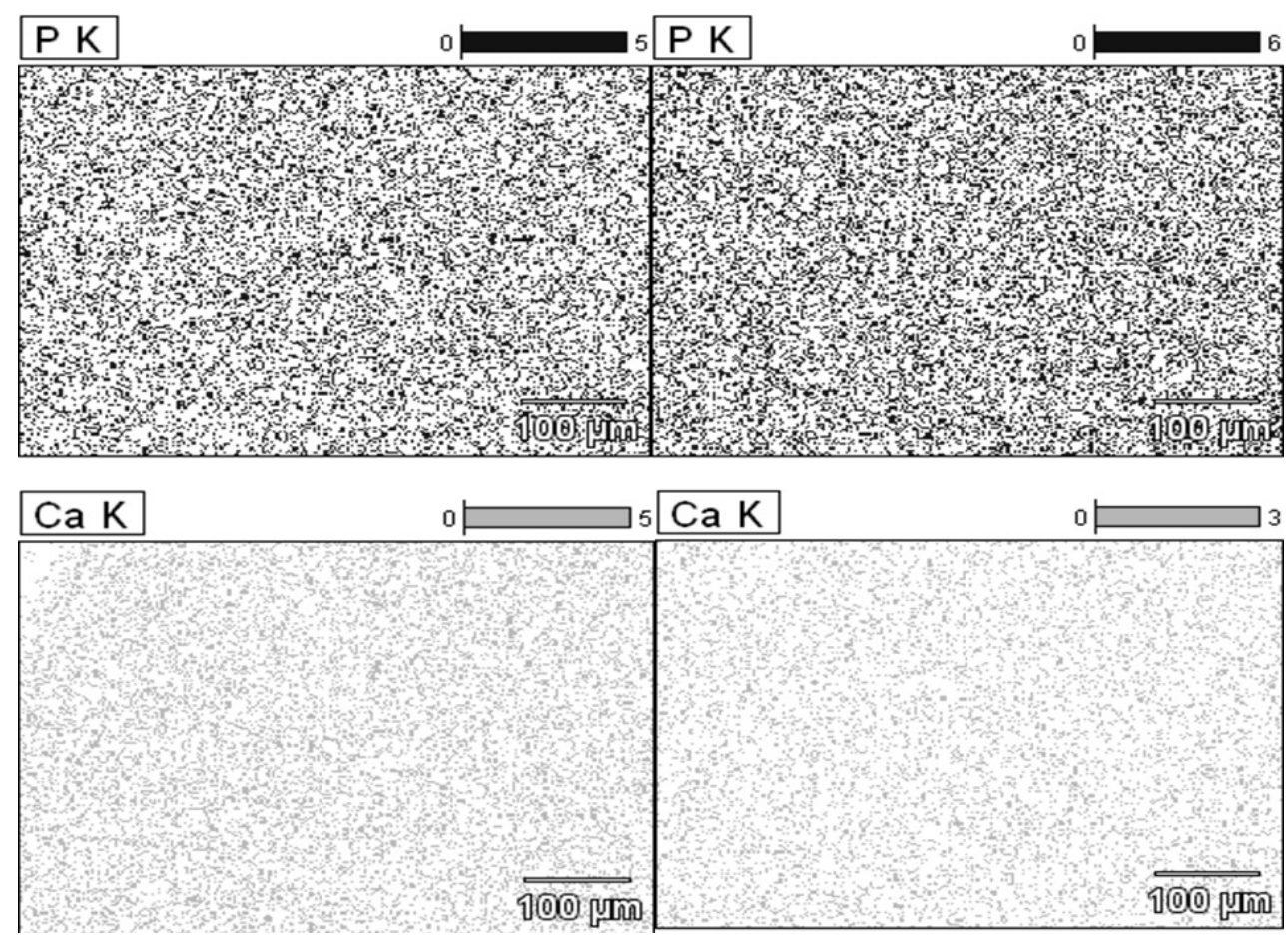

Fig 1: The distribution of calcium and phosphate to the tooth surface was shown to be uniform and no difference between control and treated $(35 \%)$.
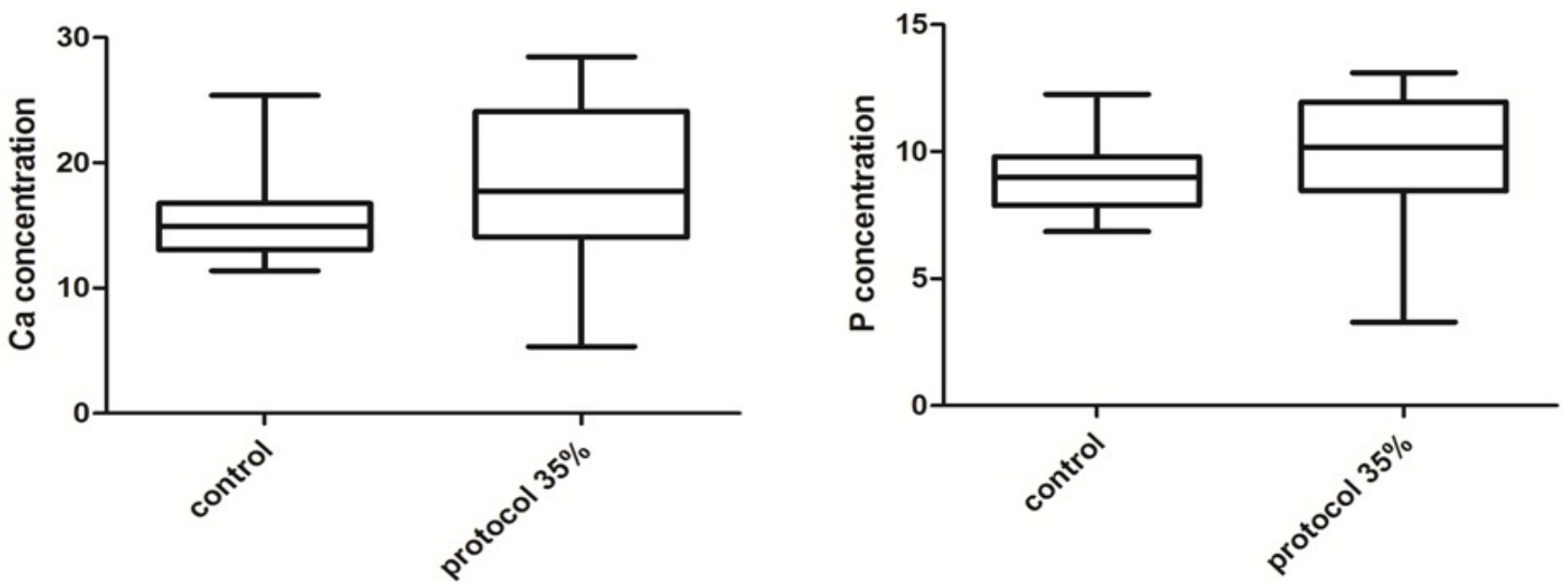

Fig 2: Graphs of relative concentration of calcium and phosphorus in the enamel (the ratio between the treated group and its control).

By analyzing graphs can be seen that the median concentrations of calcium and phosphorus are lower than the median of the controls, however despite these reductions were not statistically significant. 
The morphological evaluation of the surface enamel subjected to the action of the bleaching agent hydrogen peroxide (35\%) had no change worthy of observations, even in samples with different morphologies as can be seen in Figure 1. Being, 1B and 1D faces treated 1A and 1C and their respective controls (Fig.3).

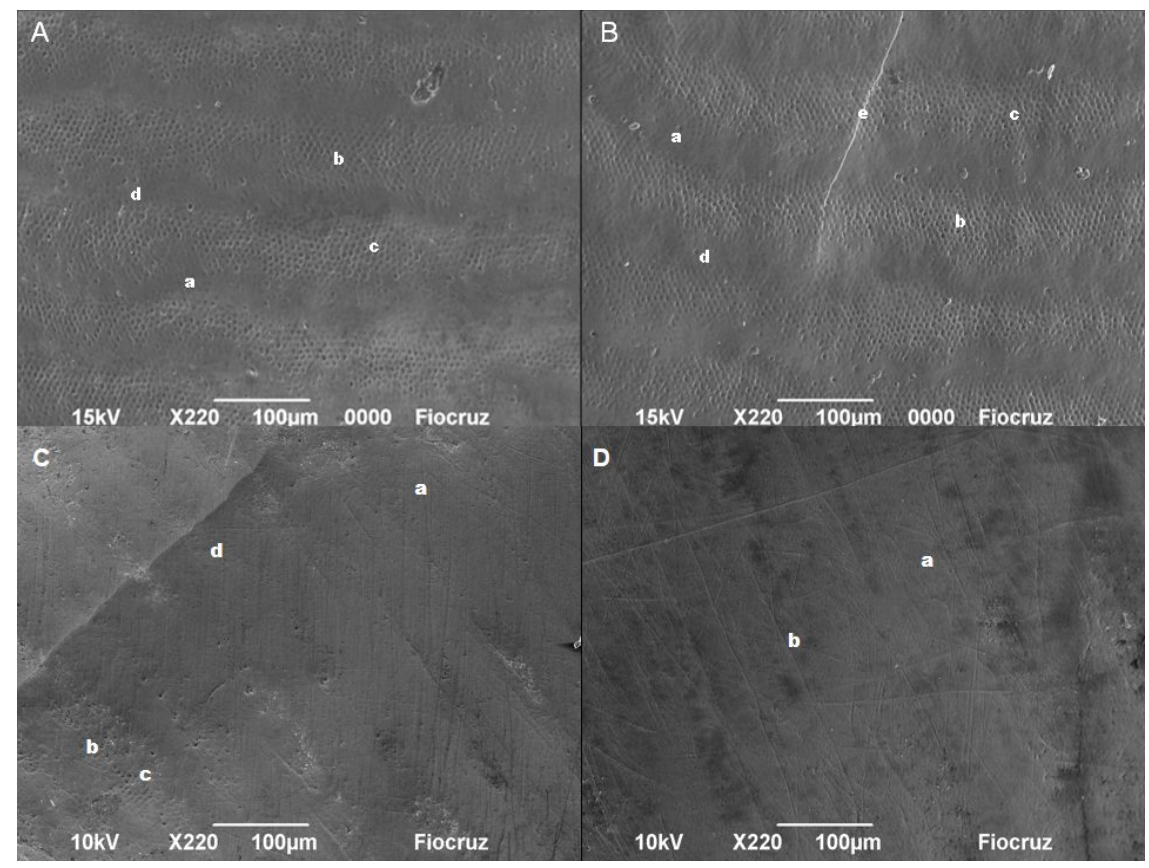

Fig 3: Topography of dental enamel: A) GCI (35\%): (a) aprismatic layer, (b) prisms, (c) interprismatic layer, (d) perikymatas. B) GExp.I (35\%): (a) aprismatic layer, (b) prisms, (c) interprismatic layer, (d) perikymatas, (e) coverslip. C) GCI (35\%): (a) aprismatic layer, (b) prisms, (c) interprismatic layer, (d) coverslip. D) GExp.I (35\%): (a) aprismatic layer, (b) slots.

\section{DISCUSSION}

The standardization of the sample in this study was designed for evaluation of nanomorphology enamel, this standardization is necessary because of the differences in enamel samples of existing. To be faithful this standardization was the same tooth used to be photobleached while being its own control, this control with the evaluation of the research is more accurate. Some studies already see the standardization using a single tooth for all tests when evaluating the change in temperature from different light sources ${ }^{11-12}$.

Having a peak absorption wavelength of $512 \mathrm{~nm}$ the pigments of red color ${ }^{13}$, which corresponds to green light, so that light would increase the efficiency in activating the red gel and therefore chosen for this study.

The quality of life is related to oral health, patients showing teeth without embarrassment, it's difficult to maintain oral hygiene subsidiary of patients and prevent the increased sensitivity resulting from tooth bleaching. This study is a secure protocol, which limits the time the bleaching agent on the tooth surface, thus hindering the occurrence of dental hypersensitivity ${ }^{14}$.

The scientific literature has provided consistent protocol chosen for this study, where we used images obtained by scanning electron microscopy analysis of the enamel surface, which in some studies has often derived morphological changes of bleaching with hydrogen peroxide ${ }^{15}$. This study found changes in nanomorphology enamel, however, these changes were not caused by photobleached. 
To avoid damage to the tooth structure tooth whitening activated by heat, light, laser should not raise the temperature intrapulpal more than $5,5{ }^{\circ} \mathrm{C}^{16}$. Tooth bleaching is a conservative procedure in dental esthetics, however, some studies suggest the occurrence of hypersensitivity due to penetration of the bleaching agent on dental tissues ${ }^{17}$. These results show, for the scanning electron microscopy, the presence of cracks in the enamel surface not displayed clinically and not caused by the bleaching process, this may explain the occurrence of dentinal hypersensitivity.

The enamel surface shows irregularities, "physiological slots" that can be alarged ${ }^{18}$. These observations are consistent with the present study, which was observed irregularities of tooth surfaces and the presence of grooves.

Some studies show the morphology of enamel after bleaching, presence of depression areas with craters, decreased inorganic part compromising hardness, roughness, the compromised enamel prisms ${ }^{19}$. This study found these morphological changes in the enamel surface of the experimental group and its control. Hence, there is an understanding that these changes depend on the previous history of this dental unit.

The contact time of the bleaching agent to the tooth surface and its concentration, is an important cause morphological changes in enamel surface after a procedure bleaching ${ }^{1}$. This study chose a secure protocol decreased the contact of the bleaching agent with the surface of the dental unit, this protocol was designed to single session, it reduces

the time, is the most researchers agree that the expansion of the contact time of the agent bleaching with the tooth surface is the main factor for the morphological changes. The success of this study may have been at one single-session protocol.

The appearance of tooth enamel can be modified by the concentration of hydrogen peroxide ${ }^{20}$. This factor was not relevant in the present study, it was the use of concentration (35\%) and compared with their controls, which was the tooth itself, there was no morphological changes.

An important causal variable that sets the appearance of lesions in dental enamel is the $\mathrm{pH}$ of hydrogen peroxide ${ }^{20}$. The photo bleaching gels have assisted the $\mathrm{pH}$ buffered, differing from the home whitening gels, which have acidic $\mathrm{pH}$, around two ${ }^{1}$. This factor may have contributed to the results of this study, since the bleaching agent used was neutral $\mathrm{pH}$, preventing demineralization of tooth enamel.

The protocol of dental bleaching when done correctly, regardless of their mode of activation or concentration of the bleaching agent, no prejudicial change will occur on the surface of dental enamel clinical point of view ${ }^{21}$. The result of this study agrees with the understanding that the protocol can be the difference of the results found in the literature.

\section{CONCLUSION}

The scanning electron microscopy before their analysis allowed us to infer that there are striking morphological differences between the enamel samples. Highlighting the need to use the same tooth for comparative morphological studies. The photoassisted whitening with green LED and treatment with a concentration of $35 \%$ hydrogen peroxide, did not cause morphological changes in the enamel surface or mineral when compared to their respective controls.

\section{ACKNOWLEDGMENTS}

Work at the author's laboratories was supported by grants from Conselho Nacional de Desenvolvimento Científico e Tecnológico (CNPq) and Centro de Pesquisas Gonçalo Muniz, Fundação Oswaldo Cruz (FIOCRUZ). 


\section{REFERENCES}

[1] Pinheiro, A.L.B., Brugnera, Jr. A., Zanin, F. [Aplicação do laser na Odontologia], Editora Santos, São Paulo, 203243(2010).

[2] Saba-Chujfi, E., Cicareli, A. J., Zanin, F. [Odontologia: resultados e integração], Editora Santos, São Paulo 145-64 (2008).

[3] Haywood, V.B., Heymann, H.O. “Nightguard Vital bleaching,” Quint. Int. 20(2), 173-176 (1989).

[4]Campagnoli, K.R., Scholz Jr., N. "Clareamento de Dentes Desvitalizados: técnica LED com peróxido de Hidrogênio," Ver. Clín. Pesq. Odontol. 4(2), 107-112 (2008).

[5] Kossatz, S., Dalanhol, A.P., Cunha, T., Loguercio, A., Reis, A., "Effect of light activation on tooth sensitivity after in-office bleaching.," Oper. Dent. 36 (3), 251-7 (2011).

[6] Do Carmo P.J., D'Arce M.B., Ambrosano G.M., Aguiar F.H., Lovadino J.R., Paulillo L.A., Lima D.A., "Efficacy of tooth bleaching with the prior application of a desensitizing agent," J. Investig. Clin. Dent. ,DOI: 10.1111/jicd.12074 (2013).

[7] Zanin, F.A.A., Brugnera Jr., A. “Clareamento dental com luz laser.” RGO , 40(5), 1-42 (2002).

[8] Zanin, F., Windlin, M.C., Brugnera, A.P., Brugnera Jr., A. "Photo activated dental bleaching: bioscience in clinical practice," Imp. News , 9(1), 53-57 (2012).

[9] Malvar, M.F.G., Albergaria, S.J.S., Lenzi, H., Sampaio, S.C.P.O., Araújo, R.P.C. "Estudo da Ação do EDTA Sobre a Camada Residual,” Pesq. Bras. Odontoped. Clin. Integr. 9(3), 367-372 (2009).

[10] Zanin, F.A.A., Brugnera Jr., A.,Bassoukou, I.H. "Novo protocolo com LEDs verdes para o clareamento dental," RGO . 54(4), 340-344 (2006).

[11] Sulieman, M. Addy, M., Macdonald, E., Rees, J.S. "The bleaching depth of a 35\% hydrogen peroxide based inoffice product: a study in vitro," J. Dent. Bristol. 33(1), 33-40 (2005).

[12] Sulieman, M., Addy, M., Ress, J.S. "Surface and intrapulpal temperature rises during tooth bleaching: an In vitro study," Br. Dent. J. 200, 631-634 (2006).

[13] Rocha, R. "Interação dos lasers com diferentes agentes clareadores," Programa Oficial, Abstrats, Laser Odonto. Show 11 (2003).

[14] Meireles S.S., Goettems, M.L., Dantas, R.V., Bona, A.D., Santos, I.S., Demarco, F.F. "Changes in oral health related quality of life after dental bleaching in a double-blind randomized clinical trial" J. Dent. , S0300-5712(13)003229. DOI: 10.1016/j.jdent.2013.11.022 (2013).

[15] Bitter, N.C., Sanders, J.L. "The effect of four bleaching agents on the enamel surface: a scanning electron microscopic study," Quint. Int. 24(11), 817-824 (1993).

[16] Buchalla W, Attin T. "Review External bleaching therapy with activation by heat, light or laser--a systematic review," Dent. Mater. 23(5), 586-96 (2007).

[17] Martin, J., Fernandez, E., Bahamondes,V., Werner, A., Elphick, K., Oliveira, O.B. Jr., Moncada, G. "Dentin hypersensitivity after teeth bleaching with in-office systems. Randomized clinical trial," Am. J. Dent. 26(1), 10-4. (2013).

[18] Hugo, F.N. Souza, M.A.L., Corso, A.C., Padilla, D.M.P. "Efeito erosivo in vitro de um vinho tinto brasileiro sobre o esmalte dental bovino observado em microscopia eletrônica de varredura," Rev. Odonto. Cienc. 21(51), 71-76 (2006).

[19] Fu, B., Hoth-Haning, W., Haning, M. "Effects of dental bleaching on micro and nano-morphological alterations of the enamel surface," Amer. J. Dent. 20(1), 35-40 (2007).

[20] Pinto, C. F. Oliveira, R., Cavalli, V., Giannini, M. "Peroxide bleaching agent effects on enamel surface microhardness, roughness and morphology," Braz. Oral Res. 18(4), 306-311 (2004).

[21] Dietschi, D., Rossier, S., Krejci, I. "In vitro colorimetric evaluation of the efficacy of various bleaching methods and products," Quint. Int. 37(7), 515-526 (2006). 